\title{
Article
}

\section{Emergency Basic Income during the Pandemic}

\author{
JURGEN DE WISPELAERE and LETICIA MORALES
}

\begin{abstract}
This paper focuses on an emergency basic income (EBI) as a tool for avoiding financial insecurity during the time of pandemic. The authors argue that paying each resident a monthly cash amount for the duration of the crisis would serve to protect them from the economic fallout.They suggest three reasons why the EBI proposal is particularly well-suited to play an important role in a comprehensive public health response to COVID-19: it offers an immediate and agile response; it prioritizes the most vulnerable in the affected population; and it promotes a solidaristic response to the pandemic crisis. To go beyond the need to shut down and restart an EBI assistance scheme each time a pandemic hits, the authors propose considering turning the program into a permanent feature.
\end{abstract}

Keywords: emergency basic income (EBI); pandemic; public health; social protection

In addition to straining health systems around the world, the COVID-19 pandemic is predicted to cause a global economic and social crisis of an unprecedented scale. ${ }^{1}$ The main culprit is the radical shutdown of vast parts of the economy as part of a comprehensive public health strategy to combat the coronavirus that at the height of the peak insisted on stringent lockdown, quarantine, and physical distancing measures. Public health officials argue the disastrous impact on the global economy is justified because mitigating the spread of the virus saves many lives, especially among the elderly and those with pre-existing medical conditions. ${ }^{2}$ In addition, when left to spread, the economy would be severely damaged while subjecting workers and consumers to constant risk.

The lockdown measures, however justified, come at a severe economic and social cost. The World Bank expects global GDP in 2020 to shrink by $5.2 \%$, which amounts to the largest recession since $1945 .^{3}$ The pandemic policy response has already caused massive working time reductions and layoffs, with the estimated total working-hour losses in the second quarter of 2020 now reaching $17.3 \%$ or 495 million full-time equivalent jobs. Recent ILO estimates of labour income losses before income support measures suggest a global decline of $10.7 \%$ during the first three quarters of 2020 , which amounts to US\$3.5 trillion or 5.5 per cent of global growth. ${ }^{4}$ Furthermore, the costs of locking down the economy are not equally distributed and more likely to affect those already socially marginalized and in a precarious and vulnerable position prepandemic much harder-hence, the pandemic response entails a clear social justice dimension.

It is worth pointing out that viewing the lockdown measures as pitching health against economic opportunity and security is mistaken. There exists ample research demonstrating the immediate as well as long-term poor health outcomes associated with bouts of unemployment, poverty and economic insecurity. ${ }^{5}$ In other words,

We are grateful to Jamie Cooke, Ian Orton and Daniel Weinstock for helpful comments on a previous draft of this paper.

Leticia Morales acknowledges funding support from Fondecyt Project No 11181060 (Judicialización y políticas sanitarias en el marco del derecho a la salud). 
the COVID-19 pandemic forces us to seriously consider health-health trade-offs, in addition to a host of other social outcomes and moral values. ${ }^{6}$ It follows that an appropriate response to the COVID-19 pandemic must include strong measures to protect individuals against economic insecurity. ${ }^{7}$ Such economic support policies are part of a comprehensive public health response to COVID-19, both as an independent ethical requirement and as a social condition ensuring the necessary buy-in across the affected population for maintaining lockdown policies over time.

Many governments have instituted measures aimed at alleviating some of the burdens of locking down the economy. The World Bank estimates that, since the start of the pandemic, 190 countries have expanded or instituted pandemic-specific social protection measures totaling a half-trillion dollars globally, with short-term cash transfer programs accounting for half of the interventions. ${ }^{8}$ But despite these dramatic efforts, many-especially the most vulnerable, marginalized, and disadvantaged in society-find themselves scrambling to make ends meet on a daily basis. In this essay, we argue for the institution of a basic income, not only as an emergency policy response to the current pandemic, but also as a tool for building resilience into the economic and social fabric of societies that are likely to face further pandemic events in the near future.

\section{Emergency Basic Income}

An emergency basic income (EBI), paying each resident a monthly cash amount with no strings attached for the duration of the pandemic crisis, could play a critical and timely role in a robust ethical pandemic policy response. EBI is modeled after the more familiar proposal of an unconditional basic income (UBI), which is paid to each individual merely for being a member of the community, without imposing a means-test or work requirement. ${ }^{9}$ The basic income proposal has seen a major revival in the past decade, in large part propelled by a series of pilots and social experiments in countries around the world-for example in Finland. ${ }^{10}$ But the COVID-19 pandemic has generated unprecedented levels of support, with decisionmakers and key stakeholders around the world calling for the urgent consideration of an EBI. ${ }^{11}$

COVID-19 has put a very different spin on what many still regard as a radical utopian proposal. EBI is distinguished from the many pandemic support schemes implemented around the world by foregoing any of the conditions that characterize selective policy responses. Entitlement is dependent neither on current or past work status, nor on an obligation to perform work or look for work in return. On the contrary, with the exception of those designated as essential workers, the only obligation is to abide by the lockdown measures imposed to combat the pandemic. EBI is also paid out without regard for other sources of income or savings, although some variants include an affluence test with a cutoff point for high-income earners. These features make the program radically different from the typical, heavily targeted social protection measures in place during normal times but are precisely what may be required in the midst of a pandemic that is spreading economic insecurity as much as viral infection.

The main difference between the EBI proposal and a UBI is that EBI is by its very nature a temporary measure geared specifically at alleviating (some of) the costs of the pandemic response. EBI programs can vary in terms of duration. The more stringent versions would likely only cover the immediate lockdown period-say 
3 months - and run out as soon as said measures are entering a phase of stepwise relaxation. ${ }^{12}$ More generous schemes might allow for the fact that reopening the economy will take considerably more time-after all, lockdown restrictions are meant to be phased out very carefully over the course of several months, all the time monitoring the impact on infection rates-during which support remains vital, proposing an EBI of 6 months. Even more generous schemes could envision an EBI being paid out for the whole duration of the economic depression resulting from the pandemic, which could amount to several years of support. For obvious reasons, the shorter schemes are more likely to be politically palatable. In terms of political feasibility, the better strategy is to advocate for a short term EBI in the first instance and try to extend it for a longer period once it is already in place.

The precise level of the EBI payment is also a matter of political debate and will likely vary from jurisdiction to jurisdiction. Although even a less generous basic income will have an impact, especially on the poorest and most disadvantaged, in a context where many have lost a significant part or perhaps their sole source of income and are without savings, the case for an EBI pitched at a level that secures the most basic needs is strong. The counter-argument is usually one of financial cost, with critics often claiming a universal scheme like a EBI is simply too costly. In response, some advocates suggest an EBI could come with an affluence-test such that high-income earners are deemed ineligible. Such a restriction must apply only to the top income levels to ensure widespread buy-in from the middle-classes and to avoid any traps or lagging affecting the real targets of the scheme-lower-income recipients. ${ }^{13}$ It is worth noting that even a fully universal scheme is less costly than one might think if an EBI is combined with a dedicated progressive tax: the net cost of an EBI is always less than the gross cost. ${ }^{14}$ Of course, in the short run, it would appear the usual fiscal budget rules are no longer in operation as most governments appear quite eager to heavily borrow to provide massive economic support; in this context, the question about financing is really about whether an EBI could do a better job protecting individuals from the fallout of the current pandemic lockdown policies compared to a patchwork of targeted programs.

\section{Three Arguments in Favor of an Emergency Basic Income}

\section{An Immediate and Agile Response}

EBI stands out among the many pandemic support policies by embodying three ethical guidelines that underlie a comprehensive public health response. In the first instance, EBI constitutes a rapid response to a situation that requires an urgent intervention. Support programs must keep pace with the rapidly evolving trajectory of the pandemic and be able to offer immediate relief to populations economically affected. As countries around the world are imposing more stringent lockdown measures on wider swathes of the population, casting an ever wider restrictive net around even the most common social and economic activities, economic support measures must instantly respond to these new realities. They must also have the capacity to keep supporting people as measures are relaxed in a slow and controlled sequence, which may also include re-introducing restrictions in some cases to manage a second or even third wave of infections.

This requires an immediate policy response addressing urgent needs. It also requires policy measures that promote agility and resilience, especially in a context 
where anticipating effects is marred by complexity, uncertainty and the fact that administrative capacity itself is heavily impacted by the pandemic. ${ }^{15} \mathrm{EBI}$ is uniquely placed to function as a rapid-response economic instrument because of its lack of conditionality. The need for a bureaucratic screening mechanism to determine eligibility is excised by design, minimizing the processing time for ensuring each individual receives his or her much-needed assistance and avoiding backlogs and errors (and the need to waste bureaucratic resources on remedying such errors). ${ }^{16}$ Setting up a robust floor upon which other support mechanisms can be built makes EBI an agile policy: it is light and fast compared to the "waterfall" planning of measures that are decided from the top and then need to filter down through successive implementation stages, often encountering barriers and requiring timeconsuming adjustment along the way. ${ }^{17}$ True, EBI will still require many people to actively sign up to some sort of national register and equally each jurisdiction must decide on the fastest way to deliver the basic income grant to every person within its remit. ${ }^{18}$ These are not trivial or negligible problems but neither are they intractable, given sufficient political will.

\section{Protecting the Vulnerable}

EBI explicitly targets those most vulnerable to the economic fallout of pandemic lockdown measures. The idea that the vulnerable merit special consideration is a key feature in public health strategies and rooted in well-established social values and ethical frameworks. ${ }^{19}$ In a well-known account, Robert Goodin argued that duties to protect the vulnerable are at the very core of our moral obligations toward one another. ${ }^{20}$ Alternatively, one might regard vulnerability as a symptom that directs our obligations but are grounded in alternative moral values, such as reducing harm or mitigating need. ${ }^{21}$ In each case, public health interventions are meant to prioritize the most vulnerable in society.

Programs that are heavily targeted and rely on excessive screening often end up excluding precisely those disadvantaged and vulnerable populations that are their primary target. ${ }^{22}$ Instead, a universal program such as EBI avoids coverage gaps precisely because eligibility is automatic and guaranteed. This is particularly relevant in the case of a COVID-19 response where the vulnerable populations affected are highly diverse and belong to different policy categories: low-wage workers being furloughed or fired, workers facing reduced hours, essential workers maintaining their (often minimum wage) jobs but facing extra costs and risks while working, workers having to take time off because schools are closed and care arrangements no longer available, self-employed and gig workers-the list goes on.

These vulnerable groups are likely to share a prepandemic labor market status that offers them little social protection as well as being poor or at risk-of-poverty, leaving them with little or no economic cushion against a sudden drastic loss of income. ${ }^{23}$ But in terms of policy response, they constitute distinct groups covered by different programs with different levels of generosity. Relying on a multitude of targeted programs inevitably produces coverage gaps that disproportionately affect those most vulnerable in the current crisis, an outcome an EBI with universal coverage is guaranteed to avoid. In addition, the economic impact of a universal and uniform EBI is largest on precisely the individuals most vulnerable in terms of risking poverty and destitution. EBI is a prime example of targeting within universalism. ${ }^{24}$ 


\section{A Solidaristic Policy Response}

Finally, EBI expresses the core value of solidarity that underpins a sustained pandemic response. ${ }^{25}$ As Meena Krishnamurthy writes, with solidarity in place "citizens will be disposed to act in support of the collective as a whole and of individual members, particularly those who are the most vulnerable and in the greatest need of support." 26 Underlying any comprehensive public health response to COVID-19 is the idea that we are all in it together: the virus potentially affects us all-albeit not equally-and combatting the virus likewise requires a collective effort. But this collective effort, no matter how necessary and justified in general terms, poses an ethical challenge when the costs and burdens are distributed unequally. They pose a more severe ethical challenge if costs are left to fall disproportionately onto those who already find themselves in a vulnerable position.

This is what happens when society imposes severe lockdown measures and as a result many precarious and low-wage workers lose their jobs or are forced to reduce their hours, self-employed and gig workers see demand for their product and services fall dramatically or are prohibited from working, and small businesses are forced to close and are left without revenue. Essential workers, many of them on minimum wage contracts, are lucky to keep their jobs but now face significant risks and in many cases extra costs to earn their living. Even higher up the income ladder, we find many workers and business owners struggling as the lockdown continues. By contrast, privileged workers-for example university professors with a tenured job and the ability to work from home-and business owners may face important restrictions but not necessarily economic ruin.

We suggest that pandemic solidarity policies are best captured through the idea of proportionate burden-sharing. Solidarity understood as burden-sharing requires an economic support mechanism that compensates those most in need, therefore ensuring the economic burden of a society-wide lockdown is more proportionally shared across the population. EBI does precisely that by granting each individual a regular cash grant for however long the economic restrictions last, while using the tax system to fund the scheme in proportion to one's income. It is the EBI funding arrangement that ensures pandemic solidarity by making those whose income remains relatively protected during the COVID-19 pandemic contribute to supporting those who are facing severe destitution.

The technical specifics of how to finance an EBI goes beyond the scope of this paper but one proposal worth a brief mention is to institute a Pandemic Solidarity Levy specifically targeted to pay for the EBI. In a nutshell, the idea would be for the government to legislate for a temporary progressive solidarity tax to be implemented a year or two from now, allowing the economy to recover somewhat before adding a tax onto individuals' earnings. The time lag and a generous exemption of lower incomes also means we continue protecting those still struggling economically while progressively targeting the higher incomes that have weathered the pandemic crisis better. Instituting a specific levy rather than funding the EBI through general taxation reinforces the idea that EBI is a solidaristic policy and that a pandemic support policy must include a fair and proportionate burden-sharing arrangement.

\section{Looking to the Future: Basic Income and Pandemic Preparedness}

Thinking ahead, turning EBI into a permanent feature of the social protection universe could prove to be a critical step for promoting pandemic preparedness 
going forward. Building resilience to economic shocks associated with future waves of infectious diseases epidemiologists and public health professionals predict are inevitably coming our way may become a critical feature of pandemic preparedness. ${ }^{27}$

EBI may be a very useful tool for protecting individuals from the economic fallout during a pandemic, but the proposal is hampered by the fact that it is by definition a short-term measure that needs to be rolled out each time a new epidemic strikes; and rolled back afterwards. Even if all practical conditions are in place for the fast implementation of an EBI, the political debate necessary to legislate for this policy will inevitably be time consuming-and time is precisely what is at a premium in the midst of a pandemic lockdown. The alternative and more robust option would be to have a permanent, low-level basic income already in place that can be dialed up to the required payment level as the need arises. ${ }^{28}$ This option has two important advantages in terms of promoting pandemic preparedness. First, the implementation mechanism itself would be tried-and-tested and any kinks in the system can be worked out well in advance so that the policy is rolled out as smoothly as possible when it matters most. Second, when a pandemic breaks out and government is debating policy responses, there is an instrument already in place and all that is required is to debate how much extra funding will be put toward it.

A small-scale example of this last approach can be found in the Brazilian municipality of Maricá, near Rio de Janeiro. As the pandemic was hitting Brazil hard, Maricá was able to rapidly rollout an EBI of $\mathrm{R} \$ 300$ (€50) as part of its pandemic emergency response. It managed this by building on a program already in operation since the end of 2019 that pays a monthly basic income of $R \$ 130$ (€21) to 42,000 of its poorest residents, covering roughly 25 percent of the population. ${ }^{29}$ This is not yet a fully universal basic income scheme, but the first step of an incremental policy that over time will cover the whole population. Meanwhile, even at its current partial rollout, the Maricá experience offers a prime example of how we can implement a rapid real-time response to an emergency by ratcheting up a pre-existing schemean important lesson to consider when contemplating pandemic preparedness and socioeconomic resilience as part of a future public health strategy.

\section{Notes}

1. UNCTAD. Coronavirus: Can Policymakers Avert a Trillion-Dollar Crisis? Geneva: UNCTAD, 2020; available at https://unctad.org/en/pages/newsdetails.aspx?OriginalVersionID=2300 (last accessed 23 May 2020).

2. Gostin LO, Friedman EA, Wetter S. Responding to COVID-19: How to navigate a public health emergency legally and ethically. Hastings Center Report 2020;50:1-5.

3. World Bank. Global Economic Prospects, June 2020. Washington, DC: World Bank; 2020.

4. International Labour Organisation. ILO Monitor: COVID-19 and the world of work. Sixth edition Updated estimates and analysis. Geneva: International Labour Office; 2020; available at https: / /www.ilo.org/ wcmsp5/groups/public/—dgreports/_dcomm/documents/briefingnote/wcms_755910.pdf (last accessed 30 Nov 2020).

5. Gibson M, Hearty W, Craig P. The public health effects of interventions similar to basic income: A scoping review. Lancet Public Health 2020;5:e165-76.

6. On health-health tradeoffs in risk regulation more generally, see Sunstein CR. Health-health tradeoffs. The University of Chicago Law Review 1996;63:1533-71.

7. See note 2, Gostin et al. 2020.

8. Gentilini U, Almenfi M, Orton I, Dale P. Social Protection and Jobs Responses to COVID-19: A Real-Time Review of Country Measures; 2020 May 22; available at https://openknowledge.worldbank.org/ handle/10986/33635 (last accessed 23 May 2020). 
9. Van Parijs P, Vanderborght Y. Basic Income: A Radical Proposal for a Free Society and a Sane Economy. Cambridge, MA: Harvard University Press; 2017.

10. De Wispelaere J, Halmetoja A, Pulkka VV. The rise (and fall) of the basic income experiment in Finland. CESifo Forum 2018;19:15-9.

11. The latest special COVID-19 briefing note of the Economic Commission for Latin America and the Caribbean called for an EBI for the Latin American region. CEPAL. Informe Especial COVID-19 No3; 2020 May 12; available at https://repositorio.cepal.org/bitstream/handle/11362/45527/5/ S2000325_es.pdf (last accessed 23 May 2020). See also Molina GG, Ortiz-Juarez E. Temporary basic income: Protecting poor and vulnerable people in developing countries. Transitions Series Working Paper. New York: UNDP; 2020 July.

12. Even more stringent measures might only opt for a one-off support payment, which is typically not counted as a basic income.

13. Eyal N. Near-universal basic income. Basic Income Studies 2010;5:1-26; Spies-Butcher B, Phillips B, Henderson T. Between universalism and targeting: Exploring policy pathways for an Australian Basic Income. The Economic and Labour Relations Review 2020; online first. doi:10.1770/ 31503503406426029096644272.

14. Widerquist K. The cost of basic income: Back-of-the-envelope calculations. Basic Income Studies 2017;12:1-13.

15. Aaron Wildavsky's classic juxtaposition of anticipation and resilience as distinct modes of dealing with risk is critical in this context. Wildavsky A. Searching for Safety. New York: Routledge; 1988.

16. De Wispelaere J, Stirton S. The administrative efficiency of basic income. Policy and Politics 2011;39:115-32.

17. Mergel I, Ganapati S, Whitford AB. Agile: A new way of governing. Public Administration Review 2020; online first. doi:10.1111/puar.13202.

18. De Wispelaere J, Stirton L. A disarmingly simple idea? Practical bottlenecks in the implementation of a universal basic income. International Social Security Review 2012;65:103-21.

19. Mechanic D, Tanner J. Vulnerable people, groups, and populations: Societal view. Health Affairs 2007;26:1220-30.; Baylis, F, Kenny NP, Sherwin, S. A relational account of public health ethics. Public Health Ethics 2008;1:196-209.

20. Goodin RE. Protecting the Vulnerable: A Reanalysis of Our Social Responsibilities. Chicago: University of Chicago Press; 1985.

21. Mackenzie C, Rogers W, Dodds S. What is vulnerability and why does it matter for moral theory? In: Mackenzie C, Rogers W, Dodds S, eds. Vulnerability: New Essays in Ethics and Feminist Philosophy. New York: Oxford University Press; 2014.

22. Korpi W, Palme J. The paradox of redistribution and strategies of equality: Welfare state institutions, inequality, and poverty in the Western Countries. American Sociological Review 1998;63:661-87.; Jacques O, Noël A. The case for welfare state universalism, or the lasting relevance of the paradox of redistribution. Journal of European Social Policy 2018;28:70-85.

23. They are also more likely to affect women and ethnic or racial minority groups because these groups are disproportionately represented in precarious labor market positions.

24. Skocpol T. Targeting within universalism: Politically viable policies to combat poverty in the United States. In: Jencks C, Peterson PE, eds. The Urban Underclass. Washington, DC: The Brookings Institution; 1991.

25. Dawson A, Jennings B. The place of solidarity in public health ethics. Public Health Reviews 2012;34:65-79.

26. Krishnamurthy M. Political solidarity, justice and public health. Public Health Ethics 2013;6:129-41, at132.

27. Madhav N, Oppenheim B, Gallivan M, Mulembakani P, Rubin E, Wolfe N. Pandemics: Risks, impacts, and mitigation. In: Jamison DT, Gelband H, Horton S, Jha P, Laxminarayan R, Mock CN, et al., eds. Disease Control Priorities: Improving Health and Reducing Poverty. Washington DC: World Bank; 2018.

28. Cooke J, De Wispelaere J. Basic income and pandemic preparedness policy. Green European Journal; 2020 May 18; available at: https:/ / www.greeneuropeanjournal.eu/basic-income-and-pandemicpreparedness (last accessed 23 May 2020).

29. Katz P, Ferreira L. What a solidarity economy looks like. Boston Review; 2020 April; available at https:/ / bostonreview.net/class-inequality / paul-katz-leandro-ferreria-brazil-basic-income-marica (last accessed 23 May 2020). 